\title{
In vivo talocrural and subtalar kinematics during nonweightbearing and weightbearing dorsiflexion-plantarflexion activities
}

\author{
S Yamaguchi ${ }^{1}$, T Sasho ${ }^{2}$, H Kato $^{3}$ and SA Banks*1
}

Address: ${ }^{1}$ Department of Mechanical and Aerospace Engineering, University of Florida, USA, ${ }^{2}$ Department of Orthopaedic Surgery, Graduate School of Medicine, Chiba University, Japan and ${ }^{3}$ Department of Radiological Technology, Chiba University Hospital, Japan

Email: SA Banks* - banks@ufl.edu

* Corresponding author

from Ist Congress of the International Foot \& Ankle Biomechanics (i-FAB) community

Bologna, Italy. 4-6 September 2008

Published: 26 September 2008

Journal of Foot and Ankle Research 2008, I (Suppl I):O33 doi:I0.I I86/I757-I I46-I-SI-O33

This abstract is available from: http://www.jfootankleres.com/content/I/SI/O33

(c) 2008 Yamaguchi et al; licensee BioMed Central Ltd.

\section{Introduction}

Understanding of the effect of weightbearing on the kinematics of the subtalar and talocrural joints is critical for the diagnosis and treatment of foot and ankle disorders. However, precise kinematics of these joints during dynamic activities in vivo is not well studied. The purpose of this study was to compare in vivo kinematics of these joints during nonweightbearing and weightbearing activities in healthy subjects.

\section{Methods}

Seven healthy subjects with a mean age of $32 \pm 7$ years were enrolled. Nonweightbearing and weightbearing activities from dorsiflexion to plantarflexion were recorded with oblique lateral fluoroscopy at 7.5 frames/ sec. Geometric bone models of the tibia/fibula, talus, and calcaneus were created from CT images of the subject. Anatomic coordinate systems were embedded in each bone model. Three dimensional kinematics of the subtalar, talocrural, and ankle joint complex were determined using 3D-2D model registration techniques (Figure 1) $[1,2]$. Bone models were projected onto the distortioncorrected fluoroscopic image, and three dimensional positions and orientations of the bones were determined by matching the silhouette of the bone models with the silhouette of the image.

\section{Results}

During the nonweightbearing activity from $20^{\circ}$ of dorsiflexion to $15^{\circ}$ of plantarflexion of the ankle, the subtalar joint everted by $4^{\circ}$ and dorsiflexed by $2^{\circ}$. The talocrural joint inverted by $3^{\circ}$, plantarflexed by $32^{\circ}$, and adducted

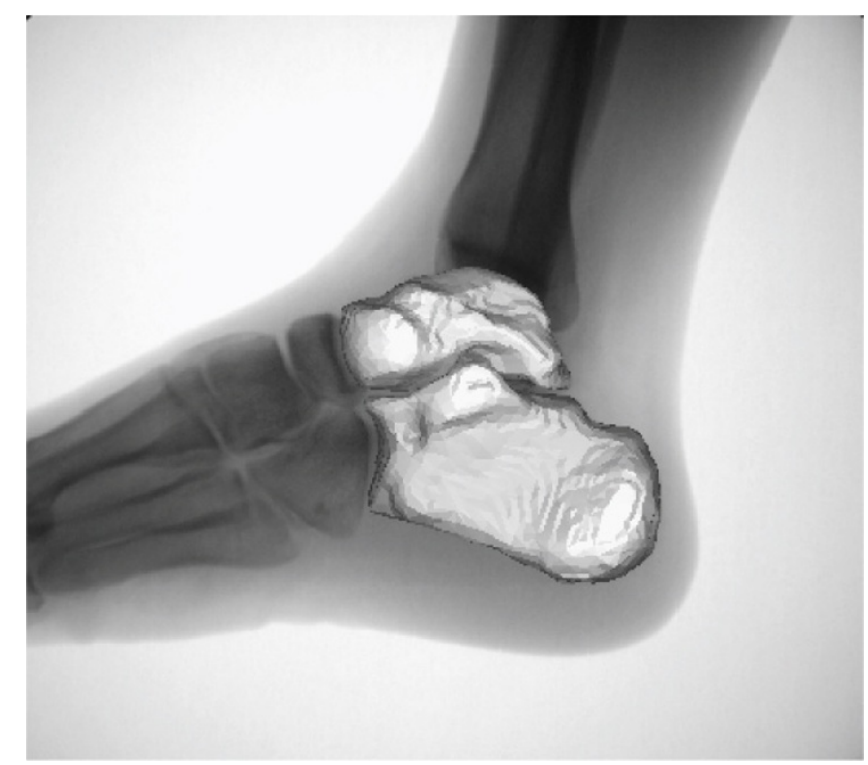

Figure I

Shape matching of the talus and calcaneus. 

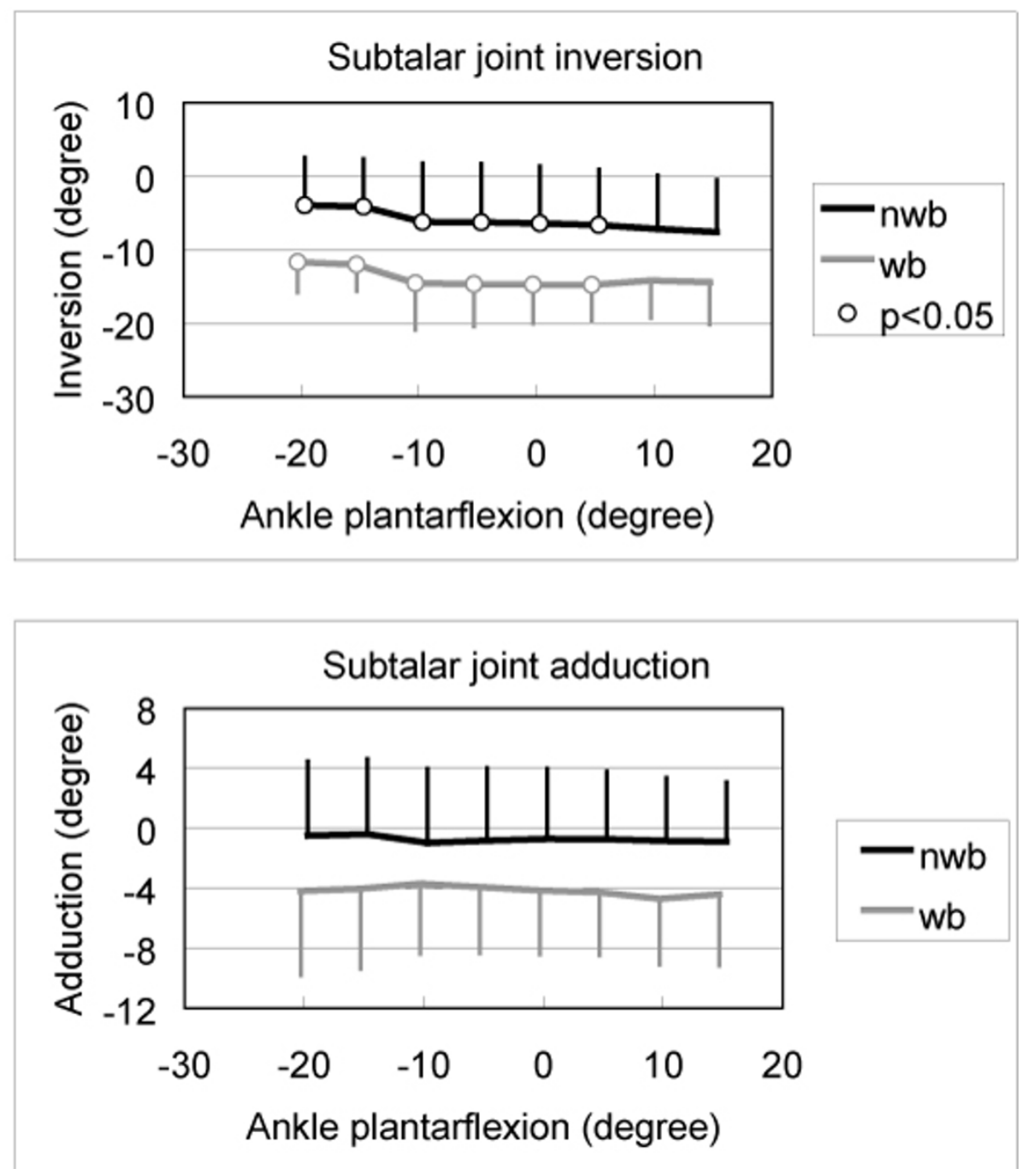

\section{Figure 2}

Subtalar joint inversion and adduction during nonweightbearing and weightbearing activities. *Significant differences in repeated measures ANOVA. ${ }^{\circ}$ Significant differences in post-hoc pair-wise comparisons.

by $7^{\circ}$. Duing the weightbearing activity, the subtalar joint was significantly more everted, $\left(7-8^{\circ}\right.$ of difference, Figure $2)$, dorsiflexed $\left(3-5^{\circ}\right)$, and abducted $\left(3-4^{\circ}\right.$, Figure 2 ) than during nonweightbearing activity. The talocrural joint was significantly more plantarflexed $\left(7-8^{\circ}\right)$ and adducted $\left(2-5^{\circ}\right)$ during weightbearing activity.

\section{Conclusion}

Coupled motion of the subtalar and talocrural joints during weightbearing activity serves to maximize joint contact area and stabilize the subtalar joint. 3D-2D model registration techniques appear to be useful tools for the quantitative analysis of the talocrural and subtalar kinematics during dynamic activities.

\section{References}

I. Banks SA, et al.: IEEE Trans Biomed Eng 1996, 43(6):638-649.

2. Moro-oka T, et al.: J Orthop Res 2006, 25(7):867-872.
Publish with Bio Med Central and every scientist can read your work free of charge

"BioMed Central will be the most significant development for disseminating the results of biomedical research in our lifetime. "

Sir Paul Nurse, Cancer Research UK

Your research papers will be:

- available free of charge to the entire biomedical community

- peer reviewed and published immediately upon acceptance

- cited in PubMed and archived on PubMed Central

- yours - you keep the copyright

Submit your manuscript here:

http://www.biomedcentral.com/info/publishing_adv.asp
BioMedcentral 